\title{
$\begin{array}{lllllllllllllll}F & E & A & T & U & R & E & & A & R & T & I & C & L & E\end{array}$
}

\section{Partial Discharge Part XXIV: The Analysis Of PD In HVDC Equipment}

Key Words: DC, partial discharge, PD testing

by

Peter Morshuis, Marc Jeroense, and

JENS BEYER

Delft University of Technology

\section{INTRODUCTION}

W take for granted that partial discharges are related to ac voltage. High voltage ac is mainly used in electrical energy supply, while high voltage dc (HVDC) is used mainly in non-energy applications. Several everyday applications make use of HVDC, including television and computer monitors with voltages up to $25 \mathrm{kV}$. In hospitals and in military applications, HVDC up to $150 \mathrm{kV}$ is found in X-ray equipment and image intensifiers. For industrial and for research applications, equipment is used with voltages up to several hundred $\mathrm{kV}$. Last but not least, a multitude of satellites orbiting our planet use HVDC in Traveling Wave Tube broadcasting equipment. The exception to all these "nonenergy" applications is the HVDC cable, which is used for submarine power transmission.

DC partial discharge tests are widely specified for military and commercial components and apparatus that are subjected to or employ HVDC. Such tests are mentioned in

ASTM 1868, where partial discharge in the context of do voltage is defined as repetitive pulses of more than one per minute. However, the understanding of phenomena in dielectrics stressed with HVDC lags far behind that associated with ac stresses. The main reason for this is the economic impact of the electrical power supply system operated at high voltage ac. A failure in the energy grid leads to tremendous costs for the users and for the utilities that produce and distribute the energy. Long service life and a high reliability are therefore required for ac components. This need for reliable products has led to intensive research and development programs, which have resulted in good knowledge of the dielectric phenomena that occur at ac high voltage, including a vast literature on partial discharges and their effect on the life of ac components.

A failure in HVDC non-energy equipment typically has fewer negative consequences than a failure of a power system component, as fewer people are affected by such a failure, and usually the faulty component can be changed at a relatively low cost. The need for a thorough understanding of dielectric ageing under $\mathrm{dc}$ voltage was thus not so compelling as for ac. The result is that very few papers on HVDC ageing or partial discharges have appeared in the literature $[2,3,5,6,7,9,11,12]$. This situation is changing rapidly. The ever-increasing need for higher reliability and smaller dimensions of non-energy dc components has resulted in a quest for a better understanding of the fundamental processes of ageing [15]. Improved design quality and reliability testing of components and systems under prolonged dc voltage stress have become major issues. Space charge can have a large effect on the electric field distribution in HVDC equipment, and an increasing number of research groups are working on space charge measurement. For testing of HVDC equipment, the detection and analysis of PD have come to play an important role $[1,12]$. This is also true for the HVDC cable that forms part of the power grid and therefore always has been the focus of attention $[4,8,10,13]$. HVDC cables play an increasingly important role in the worldwide energy grid, a good example of which are the growing number of submarine links between Scandinavia and the rest of Europe [21]. 


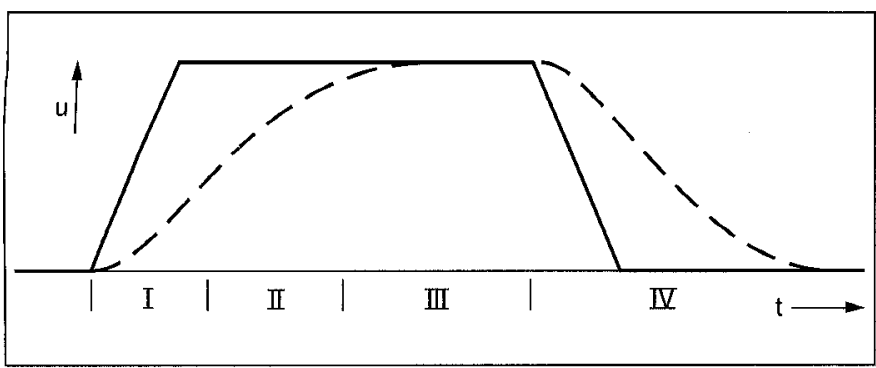

Fig. 1 Switching on and off of a dc voltage $u$. The dotted line represents the growth of internal charges. Only when this growth has finished is a pure dc field established.

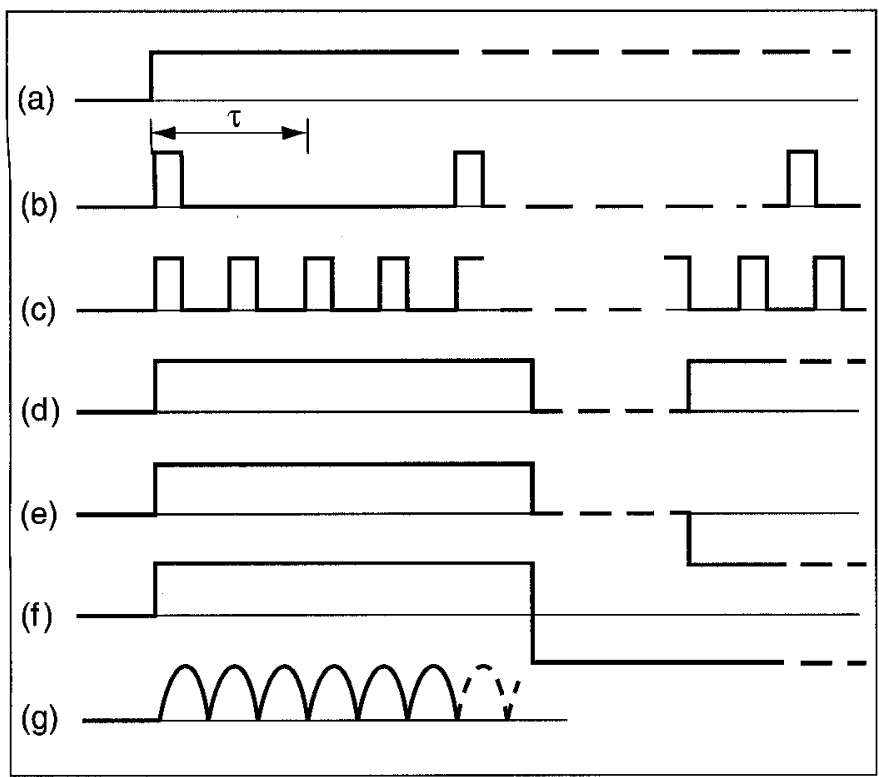

Fig. 2 Various service conditions for HVDC equipment. The electric field distribution depends on the applied voltage waveform.

In this article, we provide an overview of the results of two research projects related to HVDC, with the emphasis on the occurrence, detection, and analysis of partial discharges in dc systems. A technique developed in Delft for the interpretation of $\mathrm{dc}$ PD data is described and illustrated with examples from tests on various HVDC components.

\section{PD During DC Applied Voltage}

The risk of partial discharges under ac voltage is well known. In general, partial discharges lead to material erosion and electrical treeing, which normally results in total breakdown of the object. No hard evidence exists for a direct relationship between partial discharges at dc voltage and breakdown of the stressed object. However, partial discharges may indicate weak points in the insulation where a breakdown may be initiated by other processes. Although the partial discharges might not be the cause, they are often the predecessor of a breakdown. For this reason, measurement of partial discharges under dc excitation is very useful and often is required in standards and contracts.

\section{Stages of "DC" Excitation}

In many $\mathrm{dc}$ applications, the field distribution is not " $\mathrm{dc}$ " (i.e., resistively graded). Switching the voltage on and off, changing the polarity and duration of the voltage application, etc., result in a range of field distributions $[19,20]$, which can be divided into various stages, as shown in Fig. 1 for switching the de voltage on and off.

In stage $I$, the voltage is raised, and the capacitively graded electric field is determined by the permittivities, $\varepsilon$, the geometry of the sample, and the applied voltage. During stage II, the voltage has reached its final value, and the electric field is changing from capacitively graded to resistively graded. A pure resistively graded field is present in stage III and is determined by the conductivity $\sigma$, the geometry of the sample, the applied voltage, and the space charge density $\rho$. Consequently, the design rules for HVDC components differ from those for ac. Knowledge of the electric field in a HVDC component should not be restricted to the resistively graded field but also should extend to the capacitively graded field and intermediate situations. During stage I, the region of maximum stress may differ from that during stage III. Therefore discharges can occur during stage I that would not occur in stage III and vice versa [10]. From Fig. 2, we see that for some "dc" applications where switching occurs frequently, an ac partial discharge test might be wise. In this article, we concentrate on stage III, the pure dc field. In this case, we must test with a de voltage to obtain a field distribution similar to that under service conditions.

\section{Recurrence of Discharges at DC voltage}

In ac components, discharges recur as a result of polarity reversals. For $\mathrm{dc}$ voltage, discharges recur as well, but for other reasons. We can take the $a b c$-equivalent known from ac and extend it with leakage resistances as shown in Fig. 3. If these resistances are linear (which is not always the case), the voltage across the defect in the pure dc case will be:

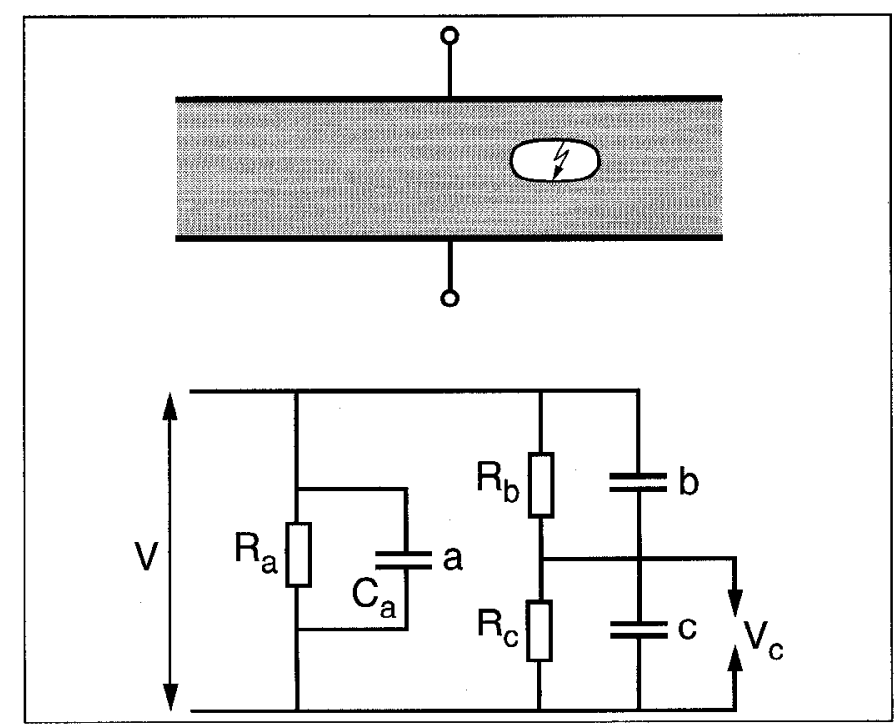

Fig. 3 The classic abc equivalent extended with leakage resistances. 


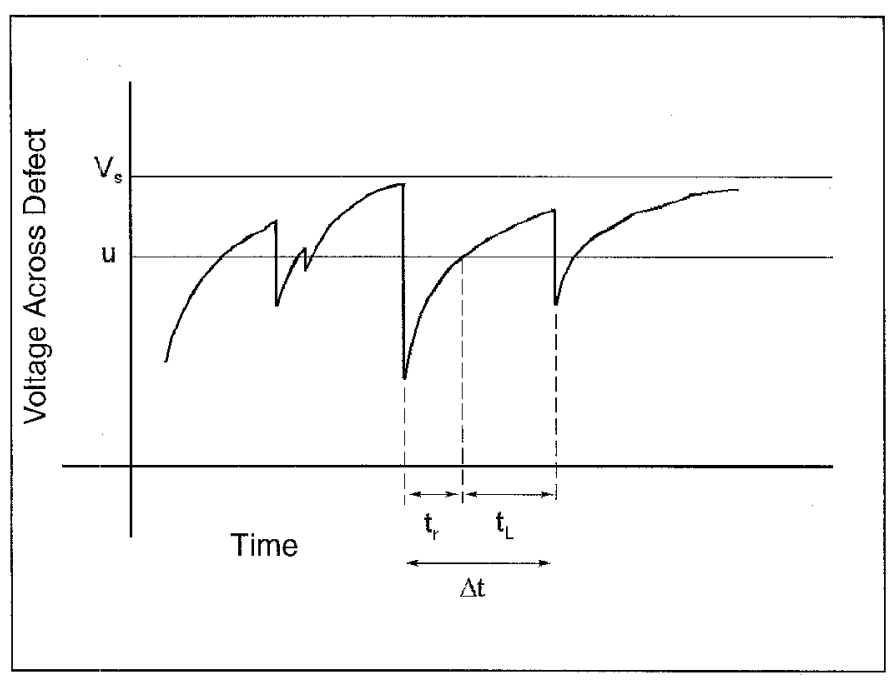

Fig. 4 Recurrence of $\mathrm{PD}$ at dc voltage. Discharge in the defect creates a relaxation oscillator in which the field across the defect builds up through resistive charging of the defect capacitance. The lumped element analog is a neon lamp connected to a dc source through a large resistor.

$$
V_{c}=\frac{R_{c}}{R_{b}+R_{c}} \cdot\left[1-\exp \left(\frac{-t}{\tau}\right)\right] \cdot V
$$

with $\mathrm{V}$ the $\mathrm{dc}$ voltage across the sample and $\tau$ a time constant, as shown in Fig. 4.

Every time the voltage across the defect reaches the breakdown voltage $u$ of the defect and if an initiatory electron is present, a discharge takes place, and the charging cycle starts again as shown in Fig. 4. The time between two discharges is equal to the recovery time $t_{r}$ plus the waiting time for an initiatory electron, the time lag $t_{L}$. The time between two discharges can be derived from Fig. 4 and is equal to

$$
\Delta t=-\tau \ln \left(1-\frac{u}{V_{s}}\right)+t_{L}
$$

with $u$ the breakdown voltage of the defect and $V_{s}$ the asymptotic value of the voltage across the defect, i.e., the voltage that eventually would be reached if the defect did not break down. For small values of $u / V_{s}$

$$
\Delta t \approx \tau \cdot \frac{u}{V_{s}}+t_{L} .
$$

The discharge repetition rate for small values of $t_{L}$ is

$$
n \approx \frac{1}{\tau} \cdot \frac{V_{s}}{u}
$$

As the generation of initiatory electrons is a statistical process, the ignition voltage of discharges varies, resulting in variations of the time between discharges and the discharge magnitude. From a statistical analysis of the time between discharges, the underlying physical processes can be inferred from the discharge data.

A special situation occurs during switching of the voltage on or off, when the electric field is capacitively graded. In these situations the rate of rise of the voltage across the de-

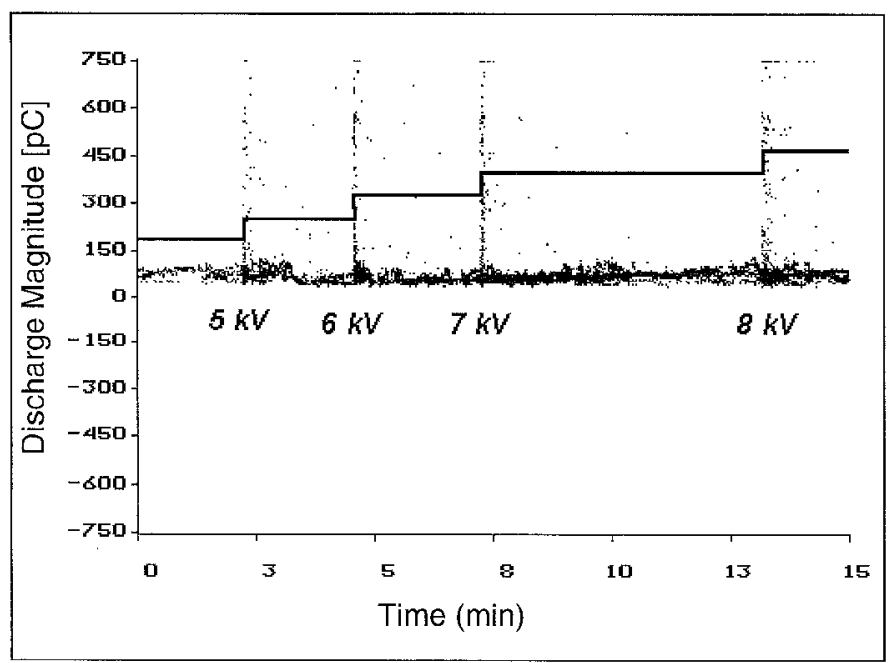

Fig. 5 The effect of raising the test voltage on the PD repetition rate and magnitude. During the rise of the voltage (stage $\mathrm{I}$ and II), the PD magnitude and repetition rate increase significantly.

fect $\mathrm{dU} / \mathrm{dt}$ is high and $\mathrm{t}_{\mathrm{r}}$ is small, resulting in a high PD repetition rate and in a high PD level. For a mean statistical time lag $t_{\mathrm{L}}$, discharges will thus ignite at higher voltages and will have a greater magnitude. This situation is shown in Fig. 5 where the test voltage on a cable is raised in steps of $1 \mathrm{kV}$.

\section{PD Detection}

Detection of discharges with dc applied voltage can be carried out in exactly the same way as for ac applied voltage. The same short current pulse flows in the external circuit and thus the theories and techniques that have been developed so extensively for ac can be used for dc as well. Fig. 6 shows the basic circuit that is used for PD detection.

Evidently the observation of discharges at dc voltage is different from that at ac voltage. For pure dc voltage the supply voltage is not periodic, and synchronous recording with $50(60) \mathrm{Hz}$ is not possible. Other techniques for representation of the discharge data have been developed. Where in the case of ac excitation the basic parameters are discharge magnitude $q$ and phase angle $\phi$, the basic parameters under $\mathrm{dc}$ ex-

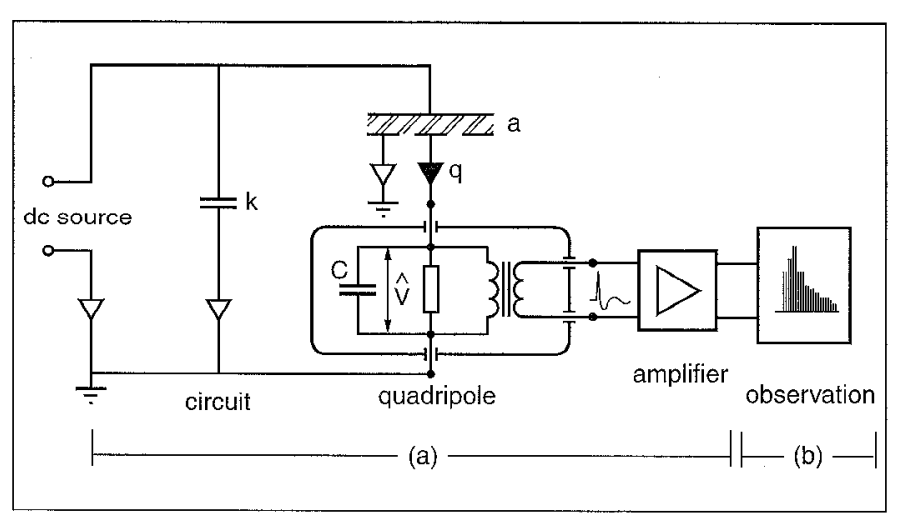

Fig. 6 Circuit for the detection of dc discharges: a) the left hand part of the circuit is identical to that for ac discharges; b)the representation of the PD data is specific for dc discharges. 


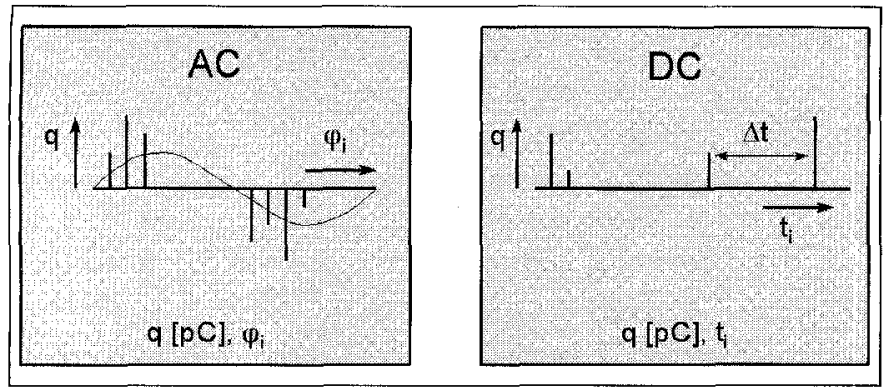

Fig. 7 Basic PD parameters for $\operatorname{ac}\left(q\right.$ and $\left.f_{i}\right)$ and for $\mathrm{dc}(q$ and $\Delta t)$.

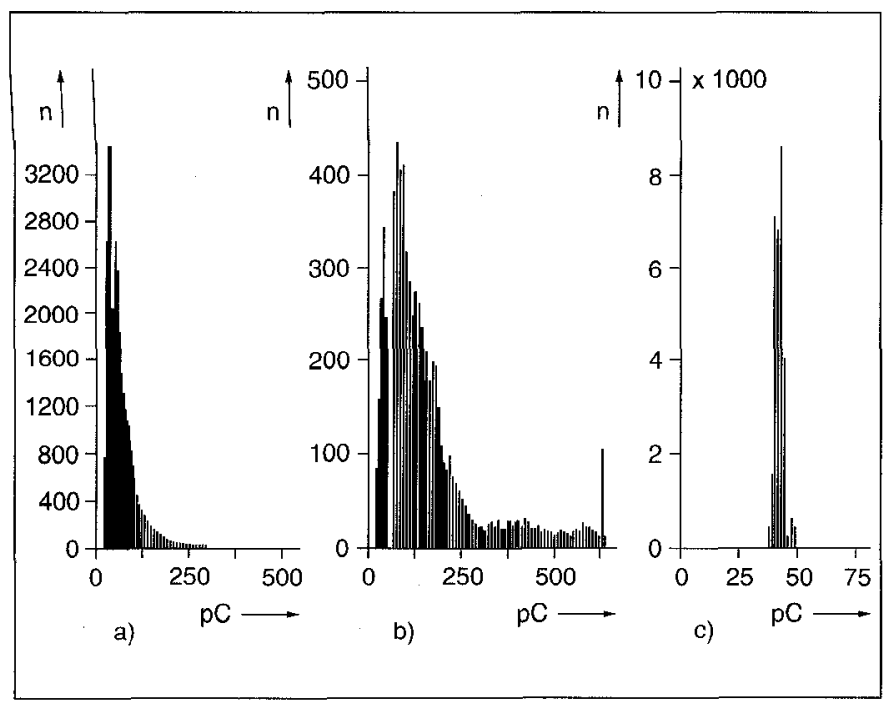

Fig. 8 PD discharge density histograms at dc, for three different types of PD: (a) cavity discharges; (b) surface discharges in air; (c) corona

citation are the discharge magnitude $q$ and the time between discharges $\Delta t$ (Fig. 7).

\section{Evaluation of PD Data}

From large numbers of measured PD data, which typically consist of PD charge and time of occurrence, various statistical distributions can be constructed. The $q-n$ or discharge density histogram as is shown in Fig. 8 is a well-known representation of PD data. Other, more intricate ways of representing the data can be useful, for example the $q-q_{\text {suc }}$ diagram that displays the mean discharge magnitude $q_{s w}$ of the successor of a discharge $q$, as is shown in Fig. 9. For a number of defect types, the relation between these two parameters can be predicted based on knowledge of the physical discharge processes. For discharges in a cavity, $q_{s u c}$ is independent of $q$. The same holds true for corona discharges, which have a very small scatter in discharge magnitude. Fig. 9 shows examples of measured $q-q_{s u c}$ diagrams. Such diagrams and distributions are used to interpret HVDC PD discharge data.

As indicated above, we can use our knowledge of the physical processes behind discharge data to evaluate PD data. A first step was taken by Fromm, who developed a mathematical model for the recurrence of discharges in cavities at $\mathrm{dc}$ voltage [1]. This model predicts two independent parameters $\Delta t_{\text {pre }}$ and $\Delta t_{\text {suc }}$ for discharges in cavities, which are
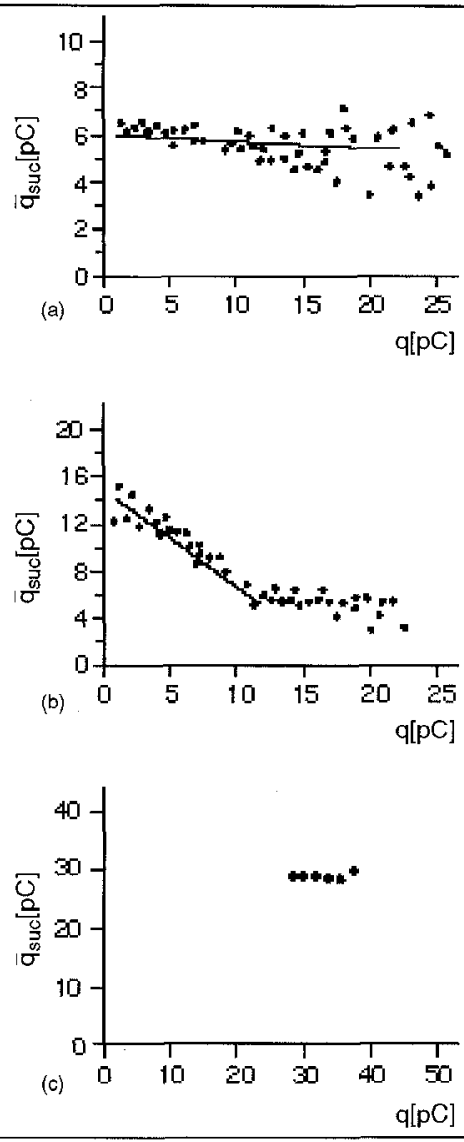

Fig. 9 The average magnitude of a discharge $q_{\text {suc }}$ following a discharge of given magnitude q: (a) cavity discharges; (b) surface discharges; (c) corona

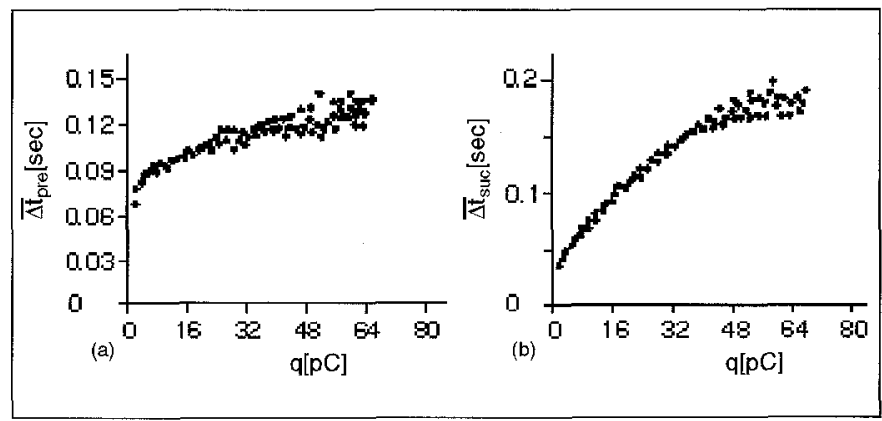

Fig. 10 Average time to (a) the predecessor of a PD of given magnitude and (b) the successor of a PD of given magnitude, for discharges in a cavity

the time to the previous PD pulse and the time to the next PD pulse, respectively. The theory predicts a linear relation between the discharge magnitude $q$ and $\Delta t_{\text {pre }}$ and $\Delta t_{\text {suc. }}$. Partial discharge tests on polyethylene samples with artificially introduced cavities showed this relationship, as seen in Fig. 10.

Using linear extrapolation, the values $\Delta \mathrm{t}_{\mathrm{suc}}(q=0)$ and $\Delta \mathrm{t}_{\mathrm{pre}}(q=0)$ can be determined, from which the mean statistical time lag and the mean recovery time (or time constant $\tau$ ) are obtained. Thus by processing the measured PD data, the physical parameters which characterize the defect can be obtained. 


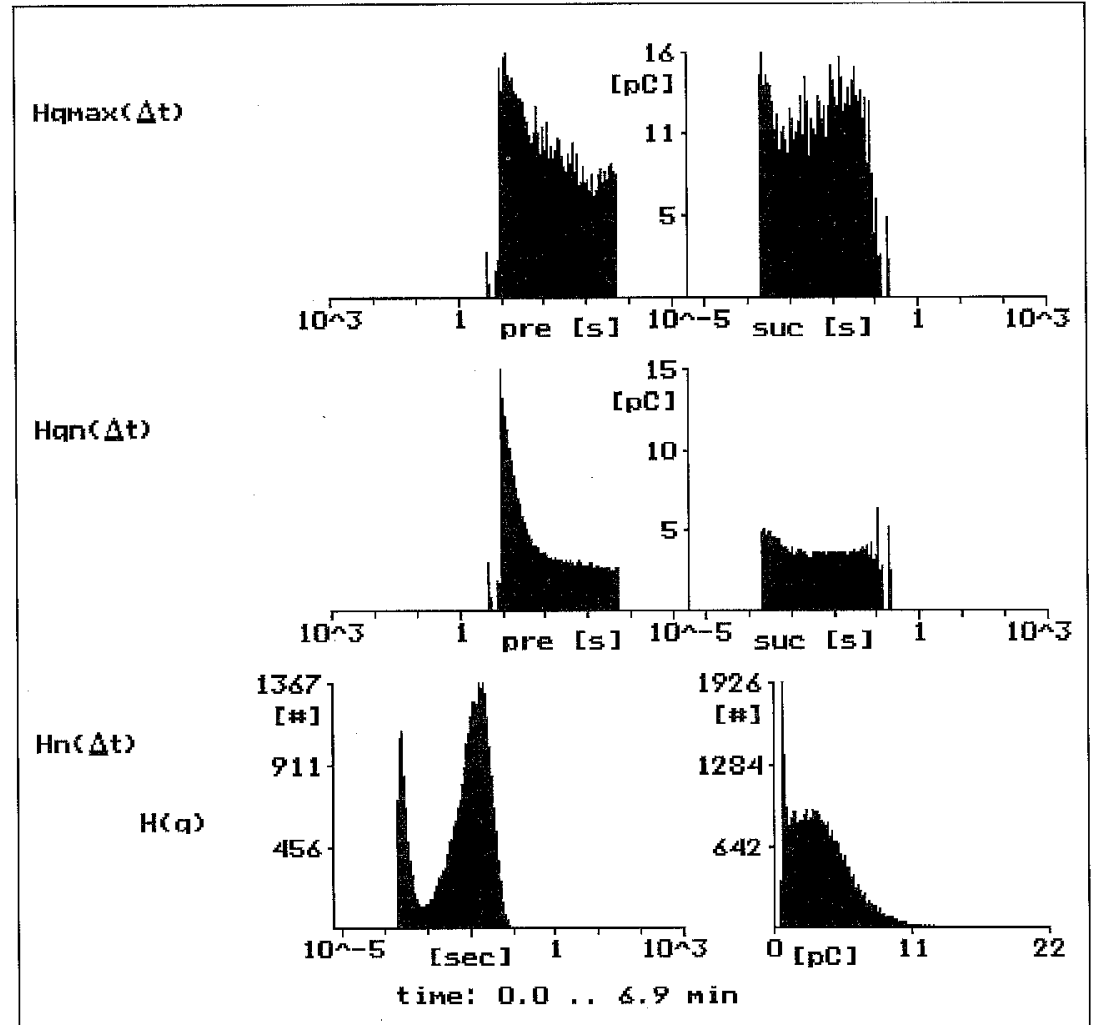

Fig. 11 Distributions of $q$ and $\Delta t$, used for classification of the discharge source

- $\mathbf{H}_{\mathrm{qmax}}\left(\Delta \mathrm{t}_{\mathrm{prc}}\right)$ and $\mathbf{H}_{\mathrm{qmax}}\left(\Delta \mathrm{t}_{\text {suc }}\right)$, representing the maximum PD magnitude as a function of $\Delta t_{\text {pre }}$ or $\Delta t_{\text {suc }}$

- $\mathrm{H}_{\mathrm{qn}}\left(\Delta \mathrm{t}_{\mathrm{pre}}\right)$ and $\mathrm{H}_{\mathrm{qn}}\left(\Delta \mathrm{t}_{\text {suc }}\right)$, representing the mean PD magnitude as a function of $\Delta t_{\text {pre }}$ or $\Delta t_{\text {suc }}$, and

- $H(q)$, representing the discharge density.

Fig. 11 gives examples of a set of these distributions.

The distributions in Fig. 11 each have a characteristic shape that depends on the defect type. These shapes can be described by a set of statistical moments. These moments are identical to those used in our laboratory for ac discharges [17] and include skewness, kurtosis, number of peaks, asymmetry and cross-correlation factor. A set of 22 statistical operators is calculated and forms a fingerprint of the discharge. Fig. 12 shows the fingerprint of discharges in oil, the distributions for which are shown in Fig. 11.

\section{Classification Technique}

To classify an unknown discharge source, a comparison is made between its fingerprint and the fingerprints stored in a database of reference defects. We used the Centour Score method [17] for comparison of measured fingerprints with those stored in the database as a result of its success for ac discharge classification. The Centour Score reflects the resemblance of the fingerprint of the unknown defect to the defects stored in the database. Many classification methods are available [18]; however, this method has the advantage of minimizing the likelihood of incorrect classification. Fig. 13 shows a block diagram of the complete classification process.

The classification technique for dc partial discharges, nicknamed ADAMS, has been developed into a product that is now used in industry (Figure 14). HVDC capacitors are tested with this system, as well as $\mathrm{X}$

\section{Classification of PD Data}

For ac, distributions and density functions of the basic parameters $q$ and $\phi$ (charge and phase) are used to describe and discriminate patterns from various defect types. For dc, the basic parameters $q$ and $\Delta t$ have been used to build distributions and density functions. The following distributions were created:

- $H_{n}(\Delta t)$, representing the number of PD pulses observed as a function of $\Delta t$, the time between successive discharges ray system power supplies, HVDC dividers, and traveling wave tubes for space applications.

\section{Artificial Defects}

To test the power of the above classification technique, data were analyzed from a series of common defects. First a database was created using the discharge data from a large number of models with artificially introduced defects, such as corona, cavities, surface discharges, and discharges in oil. 


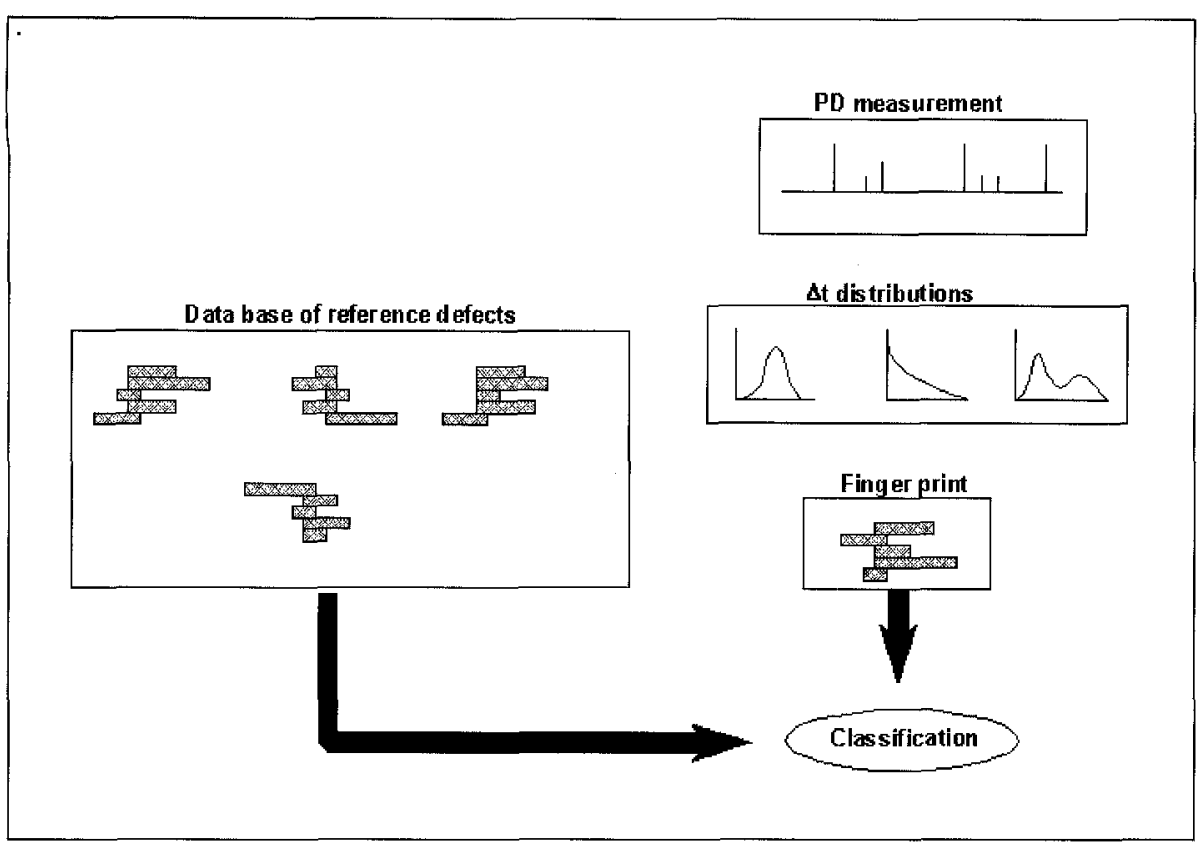

Fig. 13 Block scheme of the ADAMS classification process

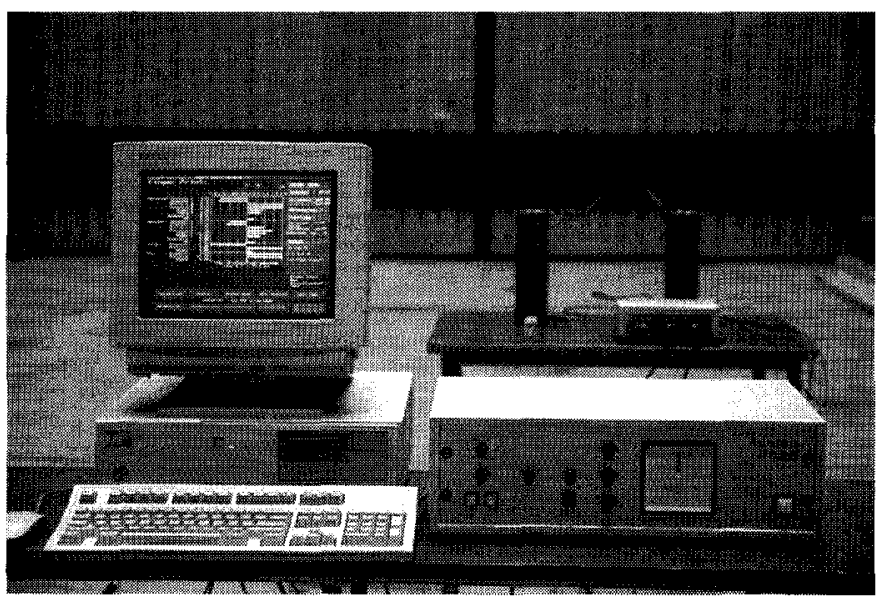

Fig. 14 The ADAMS dc partial discharge analyzer, consisting of a PD detector, a PC, and software for analyzing PD data

The next step was to make PD tests on unknown discharge sources ("unknown" means that the PD data from this discharge source were not used in creating the database). The PD fingerprint was computed from such data and was classified by the Centour Score method. The results of a number of such tests are shown in Table I. In this table, we see that no defects were incorrectly categorized.

\section{Multiple Defects}

Multiple defects commonly occur during partial discharge testing. Usually this situation leads to intricate discharge patterns that are hard to analyze. Let us make a distinction between (i) two or more sources of the same type discharging and (ii) two or more sources of two or more different types discharging. i. If the sources are exactly the same, i.e., they have equal inception voltage, equal discharge magnitude and equally shaped distributions, the source will be classified correctly. However, the number of sources cannot be determined. If the sources are of the same type but with unequal inception voltage and/or unequal discharge magnitude, they can be discriminated either by raising the test voltage carefully or by looking at the $q-t$ diagram or the density diagram of $q$, $\mathrm{H}(q)$. In the case of multiple defects, $\mathrm{H}(q)$ shows a number of peaks.

ii. If the sources are not the same, a correct classification can be obtained in a number of cases. Take for instance the case of two defects with unequal PD magnitude. In the $\mathrm{H}(q)$ diagram this is visible as two peaks, as is shown in Fig. 15. This figure displays the results of a PD test on an X-ray tube. Clearly two (or even three) peaks can be discerned. These two peaks can be analyzed separately. When the $q-q_{\text {suc }}$ diagram is plotted for each peak (Figs. 16 and 17), we can see that the physics behind the two processes differ. In fact, the pattern of peak 1 can be attributed to corona $\mathrm{PD}$ and peak 2 to another type of PD.

\section{PD Test Recommendations}

Test recommendations for PD measurements at dc voltage can be found in IEC270 [14]. IEC270 states that the number of discharges exceeding a specified magnitude should not exceed a specified total during a specified time at the test voltage. Further, IEC270 states that there is no generally accepted method for the determination of partial discharge quantities during tests with direct voltage. A commonly used definition of the discharge inception voltage

\begin{tabular}{|r|c|c|c|c|c|}
\hline \multicolumn{6}{|c|}{ Table I } \\
Average Recognition in Percent for Five Types of Measurements \\
\hline References & $\begin{array}{c}\text { Corona } \\
\text { (+ or - })\end{array}$ & PD in oil & $\begin{array}{c}\text { Electrode } \\
\text { bounded } \\
\text { cavity }\end{array}$ & $\begin{array}{c}\text { Surface } \\
\text { discharges }\end{array}$ & $\begin{array}{c}\text { Dielectric } \\
\text { bounded } \\
\text { cavity }\end{array}$ \\
\hline Measurement & & 0 & 0 & 0 & 0 \\
\hline Corona & 89 & 0 & 0 & 0 & 0 \\
\hline PD in oil & 0 & 93 & 83 & 0 & 0 \\
\hline $\begin{array}{r}\text { Electrode } \\
\text { bounded cavity }\end{array}$ & 0 & 0 & 0 & 41 & 0 \\
\hline $\begin{array}{r}\text { Surface } \\
\text { discharges }\end{array}$ & 0 & 0 & 0 & 0 & 89 \\
\hline $\begin{array}{r}\text { Dielectric } \\
\text { bounded cavity }\end{array}$ & 0 & 0 & & & \\
\hline
\end{tabular}




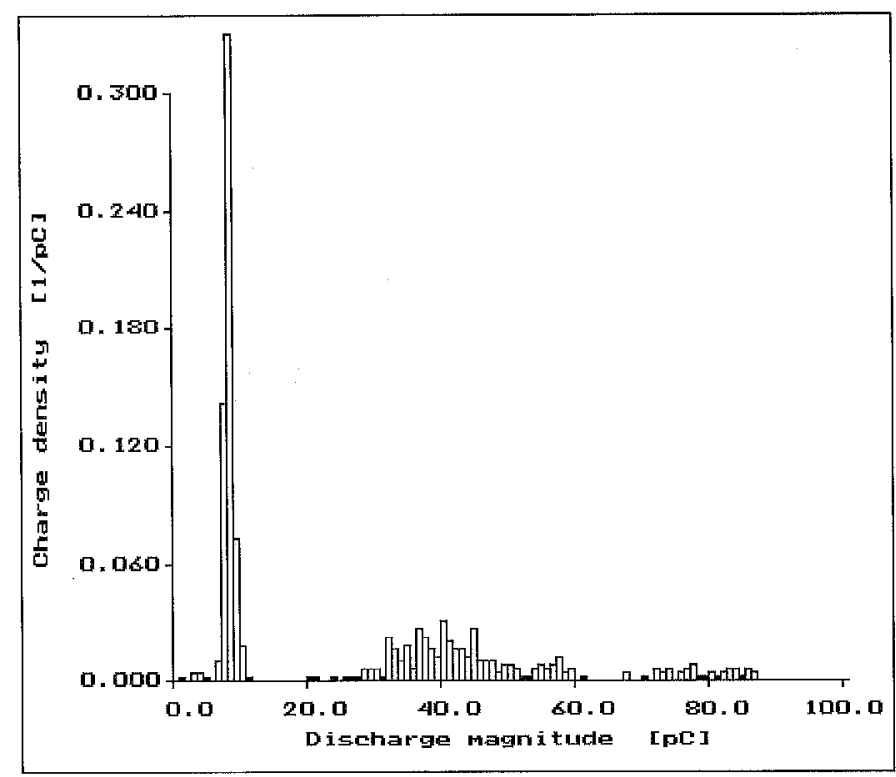

Fig. 15 Discharge density histogram for multiple defects in HVDC X-ray equipment

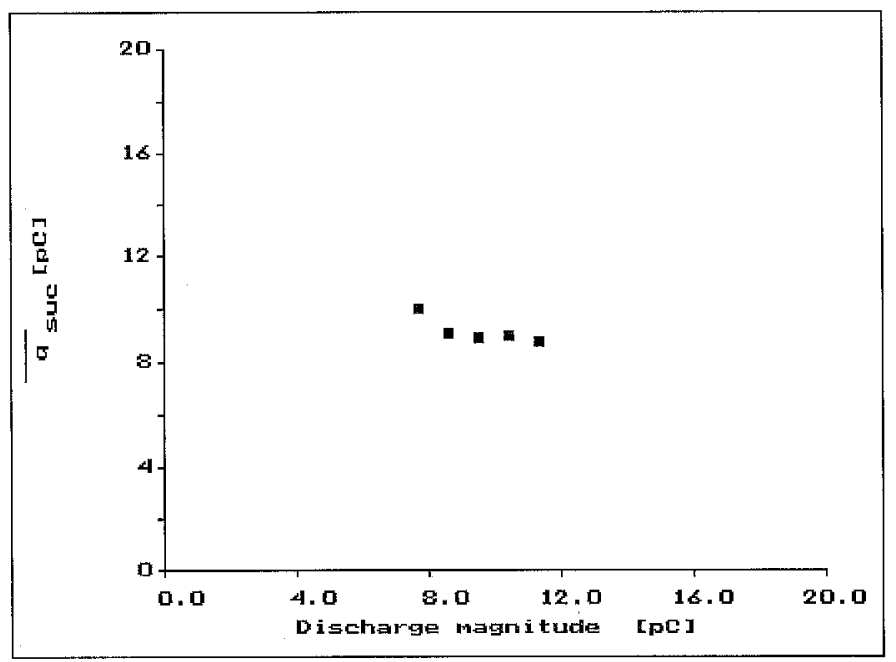

Fig. $16 q-q_{s u c}$ diagram for the left-hand peak in Fig. 15

at $\mathrm{dc}$ is the voltage at which more than one discharge per minute occurs.

PD tests performed with ADAMS deliver much more information than the number of discharges occurring per minute, examples of which will be given in the following sections.

\section{Tests on HVDC Capacitors}

The ADAMS evaluation technique was applied to $75 \mathrm{kV}$ and $150 \mathrm{kV}$ HVDC capacitors. These capacitors consist of a mixed paper-polypropylene dielectric with aluminum foil electrodes wound on a phenolic paper core and placed in a phenolic paper tube housing. Fig. 18 shows a photograph of such a capacitor, with three series windings and a capacitance of $8 \mathrm{nF}$.

The capacitor to be tested was totally submerged in transformer oil to prevent surface discharges. An identical capaci-

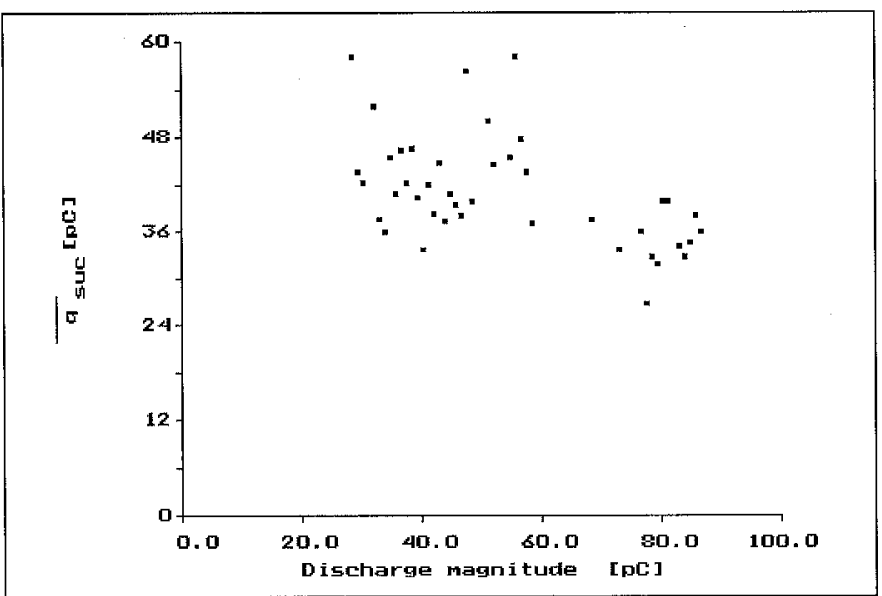

Fig. $17 q-q_{s u c}$ diagram for the right-hand peak in Fig. 15

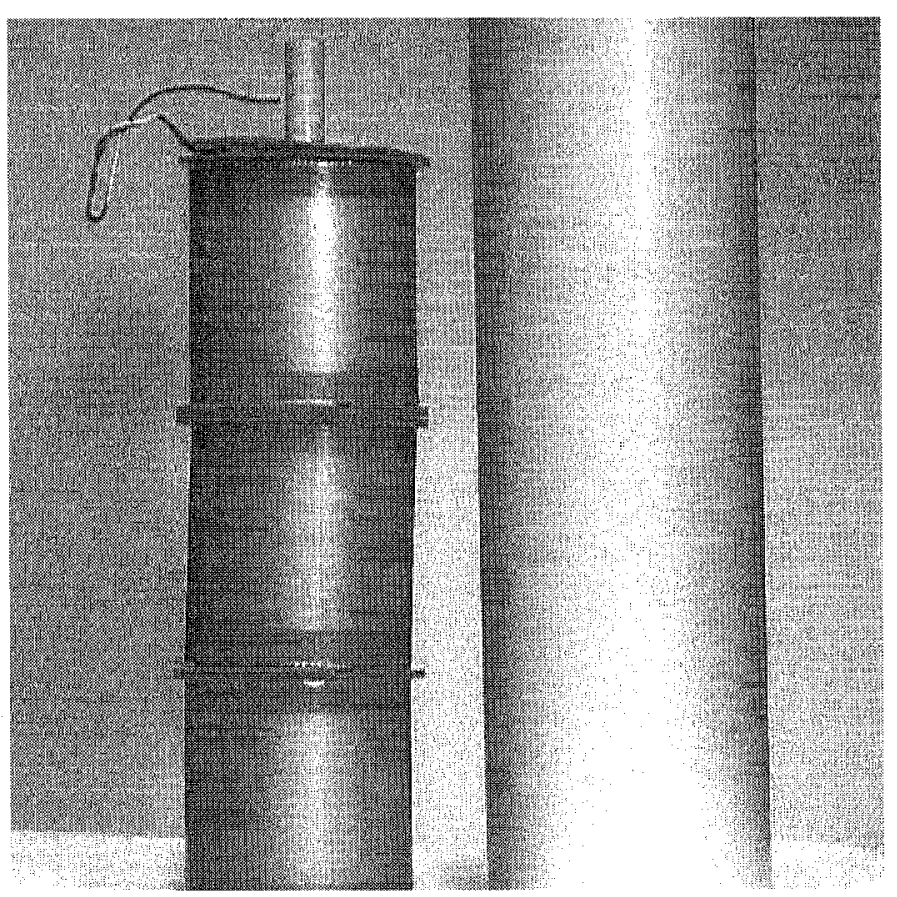

Fig. 18 Photograph of $75 \mathrm{kV}, 8 \mathrm{nF}$ HVDC capacitor. The capacitor (left) is taken out of its housing (right), which is filled with oil.

tor was used as a coupling device. Before the capacitors were tested they had been stored for four days in their testing position to allow the dielectric fluid to come to equilibrium.

In theory, discharges can occur at several sites in such a capacitor, including

- between the foils, as a result of incomplete impregnation,

- at the edges of the aluminum foils,

- at the interface between oil and (phenolic paper) tube housing,

- in gas-filled voids adhering to the outer edge of the capacitor

In practice, discharges can occur at several sites simultaneously, which makes interpretation of the PD data more difficult, but not impossible, as was shown above.

After applying the dc test voltage for ten minutes, which was sufficient time to achieve a resistive grading (i.e., dc volt- 


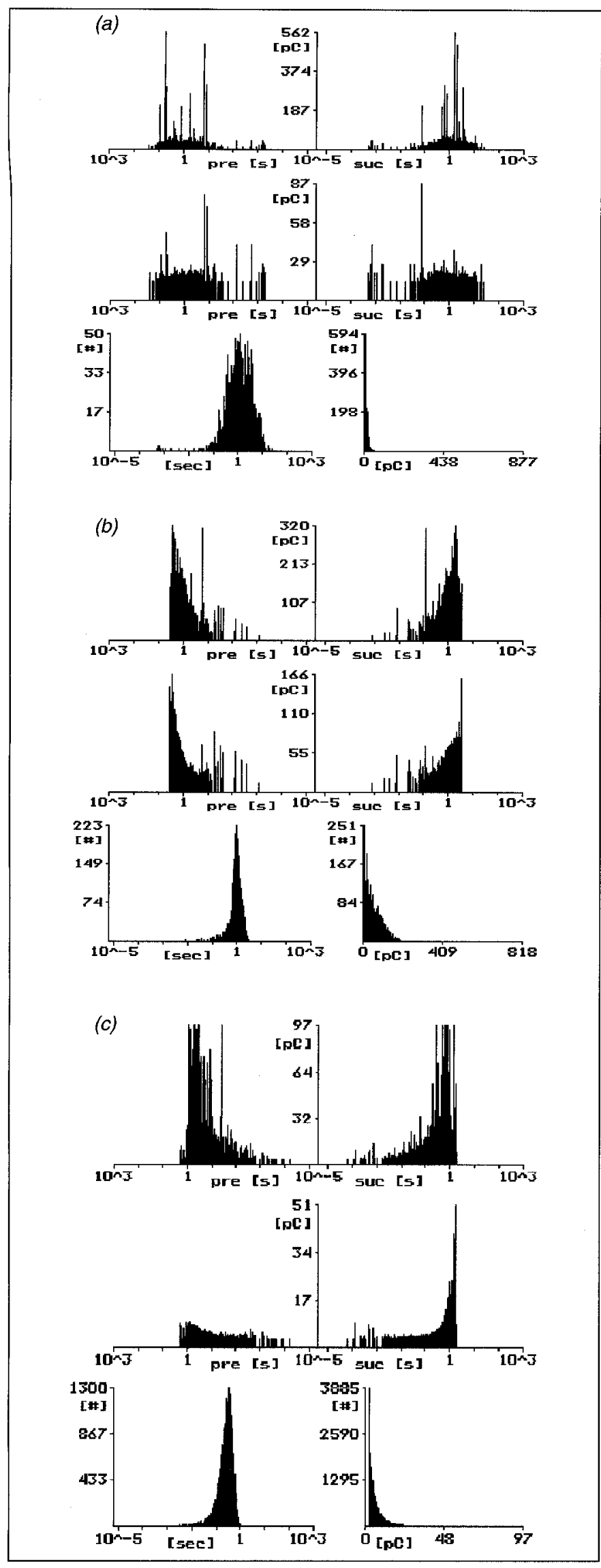

Fig. 19abc Discharge distributions for (a) undamaged $75 \mathrm{kV}, 8 \mathrm{nF}$ capacitor; (b) damaged capacitor; (c) artificial void in a model

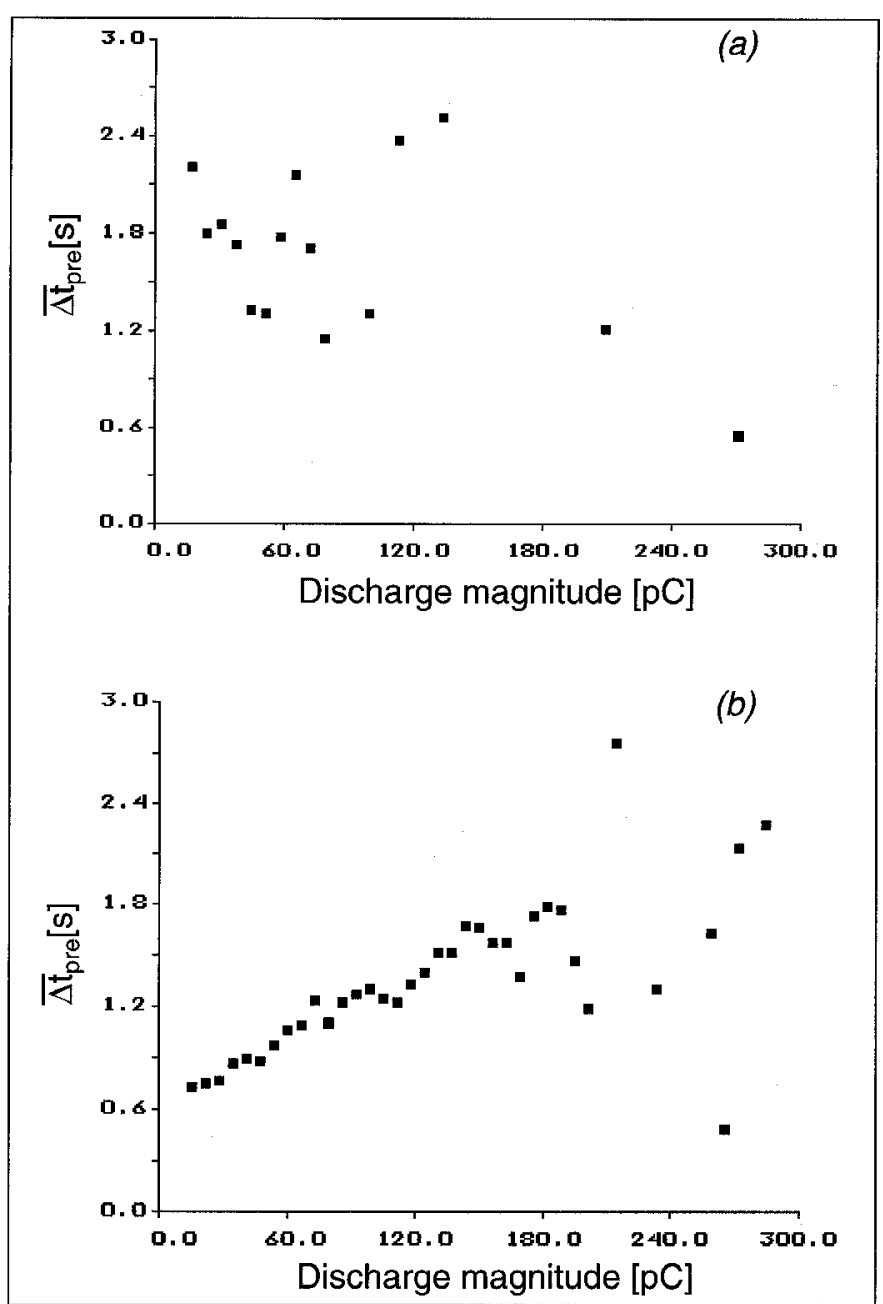

Fig. 20ab $q$ - $\Delta t_{\text {pre }}$ diagram for (a) undamaged $75 \mathrm{kV}, 8 \mathrm{nF}$ capacitor, and (b) damaged capacitor

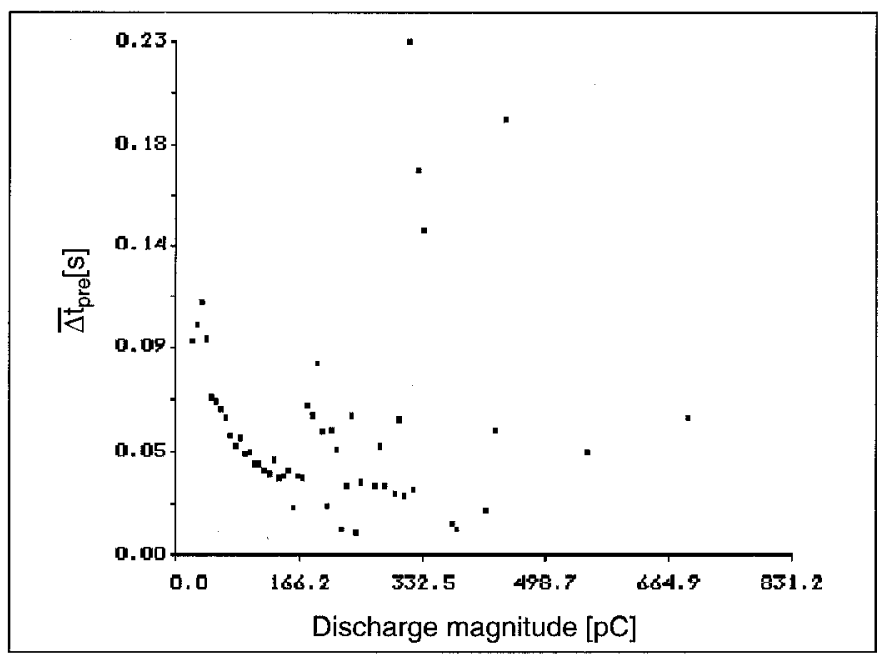

Fig. $21 q$ - $\Delta t_{\text {pre }}$ diagram for a $150 \mathrm{kV}, 20 \mathrm{nF} \mathrm{dc}$ capacitor, several hours after voltage application

age distribution) for these capacitors, the PD pulse data were recorded.

One of the $75 \mathrm{kV}$ capacitors was damaged intentionally by admitting a small amount of air. The results of PD tests on 


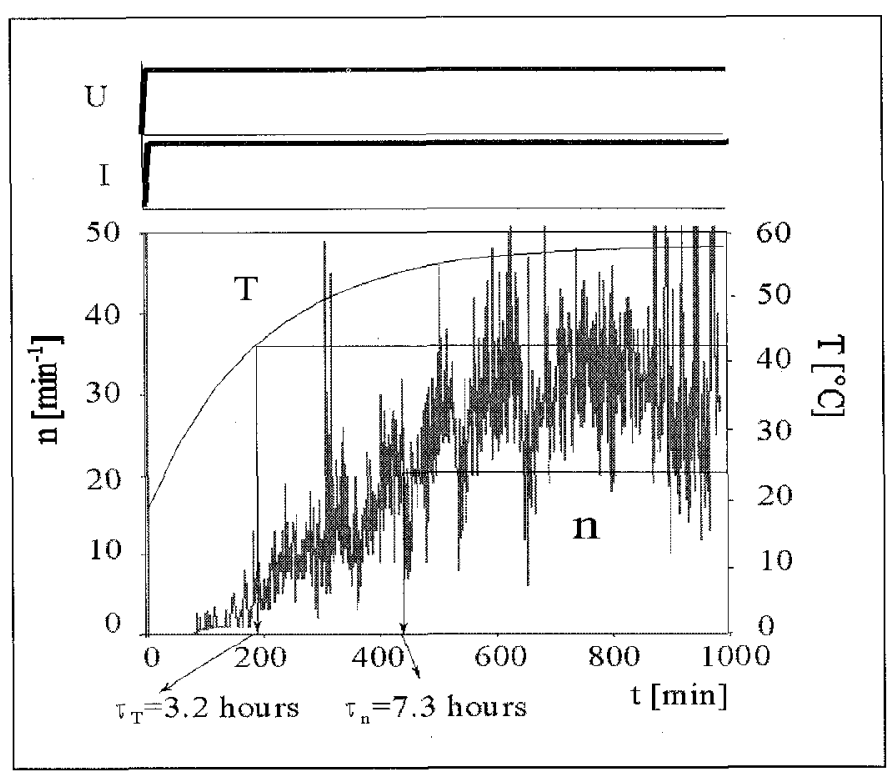

Fig. 22 The repetition rate $n$ and the temperature $T_{S}$ of the lead sheath of a mass impregnated paper cable, as a function of time during stage $I . U=-300 \mathrm{kV}, I=500 \mathrm{~A}$. Ambient temperature is $19^{\circ} \mathrm{C}$

the damaged capacitor were then compared with the results on the same capacitor before it was damaged as well as with data for other (undamaged) capacitors. Initially the results were interpreted visually by comparing the shape of the discharge distributions. Fig. $19 \mathrm{abc}$ shows the distributions for both the undamaged and the damaged capacitor, and the distributions for the two cases differ significantly. In the same figure, the distributions from an artificial void are also shown, and these resemble the distributions for the damaged capacitor. The $q$ - $\Delta t$ diagram introduced above provides an improved basis for data interpretation. Fig. 20ab shows the $q-\Delta t$ diagram of both the damaged and the undamaged capacitor. The difference is striking. The damaged capacitor shows a linear relation between $q$ and $\Delta t$, while for the undamaged specimen we see no obvious correlation between these parameters. The $q$ versus $\Delta t$ plot for the damaged capacitor can be interpreted on the basis of discharge physics, and we can state that the defect probably is a gas-filled void. Given our prior knowledge of the defect, this is not very surprising, but the result proves the power of the ADAMS technique.

A $150 \mathrm{kV}, 20 \mathrm{nF}$ capacitor (Fig. 21) showed (without being intentionally damaged) various $q-\Delta t_{\text {pre }}$ distributions. After prolonged voltage application (several hours), traces of carbon were found at the surface of the phenolic paper housing, indicating the presence of surface discharges. Fig. 21 shows the $q-\Delta t_{p r e}$ distribution after several hours of voltage application. For small values of $q, \Delta t_{\text {pre }}$ decreases linearly with $q$. A similar relationship was found previously in laboratory models with surface discharges. The physical basis of this result is explained as follows. After a large discharge a large number of new initiatory electrons are trapped at the surface. The recovery time will be large (see Fig. 4) but the time-lag will be small. Hence the next discharge will be

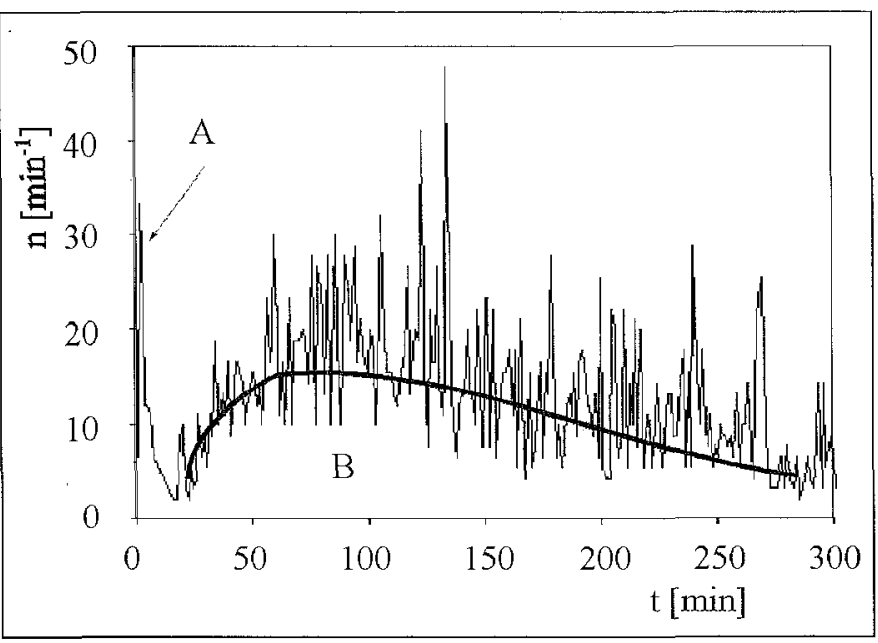

Fig. 23 The PD repetition rate as a function of time, during stage Illa. The load current is reduced to zero within a few seconds.

small. After a small discharge the recovery time is small, but few new initiatory electrons are available and the time lag will be large. Thus, the next discharge will be large, as the statistical time lag is generally much smaller than the recovery time, so that $\Delta t_{\text {pre }}$ decreases with increasing $q$.

\section{Mass-Impregnated HVDC Cable}

HVDC cables are just as reliable as high voltage ac cables in spite of less developed QA test procedures. A set of recommendations for testing of HVDC cables can be found in the ELECTRA 72 document [13]. For the development of a new generation of HVDC cables, a more advanced set of tests would be desirable. Testing for partial discharges is an important part of this set for quality assurance.

As indicated above, different stages are involved when switching dc equipment on and off (Fig. 1). The voltage $U$ and the load current $I$ may vary during these stages. As a result, the temperature distribution, the electric field, the internal pressure, the distribution of voids in the cable, the viscosity of the oil, and the conductivity of the dielectric change. This causes changes in the discharge behavior of the cable.

Some cases may have an irreversible effect on the cable. An increasing load current $I$, for example, changes the distribution of voids in the cable. Upon reducing the current to its original value, the void distribution usually will not return to its original situation.

In the following, the discharge behavior will be described during stage II (as the field changes from a capacitively to resistively graded), and in stage IIIa, when the load is switched off during pure resistive grading.

\section{Stage II}

In stage II, the external voltage has just reached its final value. We now consider the case that also the load current has just been switched on, as shown in Fig. 22. The conductor will heat and a temperature drop $\Delta T$ across the insulation will increase with time. 
The effect on the discharge repetition rate $n$ is remarkable. In Fig. 22, the increasing temperature of the lead ground shield is shown, together with the increasing discharge repetition rate. During the heating of the cable three processes take place.

i. As shown above, the PD repetition rate is proportional to the electric field. The electric field distribution in the cable changes with changing temperature distribution. The field near the conductor decreases by as much as a factor of two, while the field near the ground shield increases by a similar factor. The net result on PD activity is therefore small, unless the number of voids near the lead sheath is greater than the number near the conductor. Even in that case, the increase in the repetition rate with temperature will not be more than a factor of two.

ii. The conductivity of the insulation changes with the temperature. The higher the temperature, the higher the conductivity of the insulation, the smaller the recovery time, and the higher the PD repetition rate. The repetition rate is exponentially related to the temperature.

iii. The distribution of voids in the cable changes. With rising temperature, the oil in the insulation expands and the internal pressure increases. By this process, the number of voids is likely to decrease.

Process (ii) is thus the most probable cause for the increase of the PD repetition rate.

\section{Stage IIIa}

This is a very dangerous stage because voids are generated that are detrimental to the cable, and breakdown may occur. In this stage, the load current $I$ is reduced to zero within a few seconds while the voltage remains constant. Fig. 23 shows a typical graph of the discharge repetition rate during this stage. Two peaks appear, labeled A and B in Fig. 23. Peak A occurs just after switching off the load, and Peak B occurs one or two hours later, and has long tail of up to 10 hours duration.

The first peak is explained as the response of pre-existing voids (generated in a previous thermal cycle) to a sudden pressure drop near the conductor resulting from cooling of the cable. The second peak results from the generation of new voids by shrinkage of the dielectric. As the temperature decreases, the dielectric decreases in volume; however, the diameter of the lead sheath decreases to a lesser degree. Voids thus grow in size, mainly at the butt gaps of the taped, laminar dielectric insulation. A detailed explanation of the above described phenomena can be found in [16].

\section{Conclusions}

This article provides an overview of detection and analysis techniques for partial discharges in dc equipment. We have seen that PD analysis can extend far beyond the oldfashioned "not more than so many PD pulses per minute over a certain magnitude." Statistical analysis of PD data from dc systems can provide detailed information about de- fects. Although the time between discharges and the discharge magnitude have large scatter as a result of statistical time-lag, statistical analysis of the PD pulse pattern can provide "fingerprints" that can be compared with fingerprints for typical defects stored in a database to identify the nature of defect(s) in a component. An example of such classification was presented for $\mathrm{PD}$ in voids.

An evaluation technique was developed based on characteristic PD patterns for various defect types. Some of these defects can be recognized on the basis of their $q-\Delta t$ diagram and are thus linked with the discharge physics. For artificially introduced defects in models, the power of the ADAMS classification method using fingerprints was demonstrated. The ADAMS method is also being applied to testing of real HVDC equipment such as HVDC capacitors, for which we demonstrated that realistic defects can be detected and recognized using the $q-\Delta t$ diagram.

For HVDC submarine cable, knowledge of the discharge behavior provides insight into the behavior of HVDC cable during its different stages of operation.

Whether partial discharges are the direct cause of deterioration and breakdown in HVDC systems is still a point of discussion. However, partial discharges do indicate weak spots in a construction, and PD detection and analysis is therefore indispensable for quality control of HVDC products.

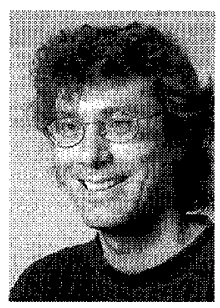

Peter Morshuss studied at the Delft University of Technology and obtained his Ph.D. in electrical engineering in 1993 on ultrawide band optical and electrical analysis of partial discharge ageing. From 1986 to 1988, he worked for the High Voltage Research Laboratory of NKF Cable in Delft, where he studied the effect of defects on cable life. Since 1988, he has been an assistant professor at the High Voltage Laboratory of the Faculty of Electrical Engineering of Delft University of Technology. He is responsible for the fields of material ageing and HVDC in a number of projects in close cooperation with industry. He can be reached at: High Voltage Laboratory, Delft University of Technology, Mekelweg 4, 2628 CD Delft, The Netherlands, E-mail: p.h.f.morshuis@et. tudelft.nl.

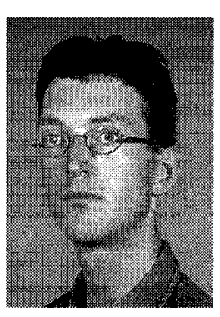

MARC JeroEnSE studied at the Advanced School of Technology in Vlissingen from 1984 to 1988. After completing his studies at Delft University of Technology in 1992, he joined the High Voltage Research Laboratory of NKF Cable in Delft and started a Ph.D. program on High Voltage Direct Current (HVDC) cables at Delft University of Technology, which he will finish in mid1997. He can be reached at: High Voltage Laboratory, Delft University of Technology, Mekelweg 4, 2628 CD Delft, The Netherlands. 


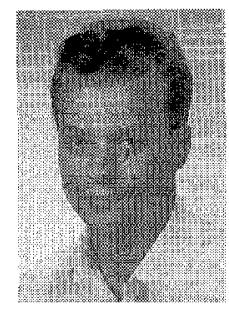

JENS BEYER received his Dipl.-Ing. in electrical engineering from Dresden University of Technology, Germany in 1994. Since 1996, he has been a Ph.D. student at the High Voltage Laboratory at Delft University of Technology. His research field covers partial discharge diagnosis and multistress ageing mechanisms at high dc voltage. He can be reached at: TU Delft, Fakulteit Elektrotechniek, Hoogspanningslab, Mekelweg 4, 2628 CD Delft, The Netherlands; Tel.: +31(0)152786204; E-mail: j.beyer@et.tudelft.nl

\section{References}

1. U. Fromm, Partial Discharge and Breakdown Testing at High DC Voltage, Delft University of Technology, The Netherlands, Delft University Press, ISBN 90-407-1155-0, 1995.

2. S. Shihab, Teilentladungen in Hoblräumen von polymeren Isolierstoffen bei boher Gleichspannung, Technische Universität Braunschweig, Germany, 1972. 3. I.M.S. Badran, O.M.B. El-Assi, S. Riazi, and B. Salvage, "Internal Discharges in Paper Insulation under Direct Voltage Conditions," VDE-IEEE Int. Symp. High Voltage Technology, Munich, Germany, 1972, pp. 396-402.

4. P.G. Priaroggia, P. Metra, and G. Miramonti, "Dielectric Phenomena in the Breakdown of Non Pressure Assisted, Impregnated Paper Insulated HVDC Cables," $4^{\text {th }}$ Int. Conf. On Conduction and Breakdown in Solid Diel., Italy, 1992, pp. 407-416.

5. J.C.J. Eeman, "Experimental Partial Discharge Detection Equipment for DC and DC Ramp High Voltage Testing," Proc. of the Europ. Space Power Conf., Florence, Sept. 2-6 1991.

6. E.F. Kelley, M. Nehmadi, R.E. Hebner, M.O. Pace, A.L. Wintenberg, T.V. Blalock, and J.V. Foust. "Measurement of Partial Discharges in Hexane under DC Voltage," IEEE Trans. on EI, Vol. 24, No. 6, 1989, pp. 1109-1119.
7. D.R.G. Melville, B. Salvage, "Detection and Measurement of Discharges in Gaseous Cavities in Solid Dielectrics under Direct Voltage Conditions," Proc. IEE, Vol. 112, No. 5, 1965, pp. 1071-1073.

8. K. Nakamura, Y. Kamijo, "Fluctuation Mechanism of DC Partial Discharge in Polyethylene and Impulse Noise in Submarine Cables," Jap. J. Appl. Physics, Vol. 15, Part 1, No. 5, 1976, pp. 865-870.

9. B. Salvage, N.R. Steinberg. "Discharge Repetition in Air-Filled Cavity in a Solid Dielectric under Direct Voltage Conditions," Electronics Letters, Vol. 2, No. 11,1966 , pp. 432-433.

10. E. Takahashi, Y. Tsutsumi, K. Okuyama, and F. Ogata, "Partial Discharge Characteristics of Oil-Immersed Insulation Systems under DC, Combined AC-DC and DC Reversed Polarity Voltage," IEEE Trans. on PAS, Vol. 95, No. 1, 1976, pp. 411-421.

11. K. Watanabe, "DC Partial Discharges and Current in Polyethylene," Jap. J. Appl. Phys., Vol. 17, Part 1, No. 3, 1978, pp. 483-490.

12. P. Werelius, R. Erikson, J.M. Braun, and H.G. Sedding," "Temporal Characteristics of Partial Discharge in Voids under DC Excitation," Nordic Ins. Symp., 1992.

13. CIGRE Study Committee 21, Working Group 21-01, "Recommendations for Tests of Power Transmission DC Cables for a Rated Voltage up to $600 \mathrm{kV}$," Electra no. 72, 1980, pp. 105-114.

14. IEC-Standard, Publication 270, "Partial Discharge Measurements," 1981.

15. F.H. Kreuger, Industrial High DC Voltage, Delft University of Technology, The Netherlands, Delft University Press, ISBN 90-407-1110-0, 1995.

16. M.J.P. Jeroense, Charges and Discharges in HVDC Cables, Delft University of Technology, The Netherlands, Delft University Press, to be published March 1997.

17. F.H. Kreuger, E. Gulski, and A. Krivda, "Classification of Partial Discharges," IEEE Trans. on EI, Vol. 28, 1993, pp. 917-931.

18. A. Krivda, "Automated Recognition of Partial Discharges," IEEE Trans. on DEI, Vol. 2, No. 5, 1995, pp. 796-821.

19. F.H. Buller, "Calculation of Electrical Stresses in DC Cable Insulation," IEEE Trans. on PAS, Vol. 86, No. 10, 1967, pp. 1169-1178.

20. C.K. Eoll, "Theory of Stress Distribution in Insulation of High-Voltage DC Cables: Part I," IEEE Trans. on EI, Vol. 10, No. 1, 1975, pp. 27-35.

21. D. Hauge, J. Normann Johnsen, T.A. Holte, and K. Bjørløw-Larsen. "Performance of the $250 \mathrm{kV}$ HVDC Skagerrak Submarine Cables," IEEE Trans. on PD, Vol. 3, No. 1, 1988, pp. 1-15. 